\title{
Energy and electron transfer reactions on silica gel and titania-silica mixed oxide surfaces
}

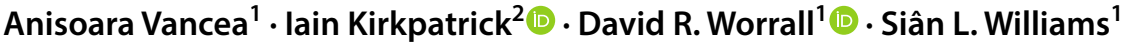

Received: 21 January 2019 / Accepted: 19 March 2019 / Published online: 2 July 2019

(c) The Author(s) 2019

\begin{abstract}
The energy and electron transfer reactions of anthracene co-adsorbed with an electron donor on silica gel and titania-silica mixed oxides have been studied by a combination of steady-state reflectance, emission spectroscopy, and nanosecond diffuse reflectance laser flash photolysis. Bimolecular rate constants for energy and electron transfer between anthracene and azulene have been measured; kinetic analysis of the decay of the anthracene triplet state and radical cation show that the kinetic parameters depend on the titania content of the sample and the azulene loading. The rate of energy and electron transfer reactions increases as a function of azulene loading and decreases with increasing titania content in titania-silica mixed oxides. These findings indicate that the observed rate of reaction is determined by the rate of diffusion of anthracene on the titania-silica surfaces, whereas, in contrast, the observed rate of reaction on silica gel is predominantly governed by the rate of diffusion of azulene.
\end{abstract}

Electronic supplementary material The online version of this article (https://doi.org/10.1007/s1116 4-019-03901-5) contains supplementary material, which is available to authorized users. 


\section{Graphic abstract}

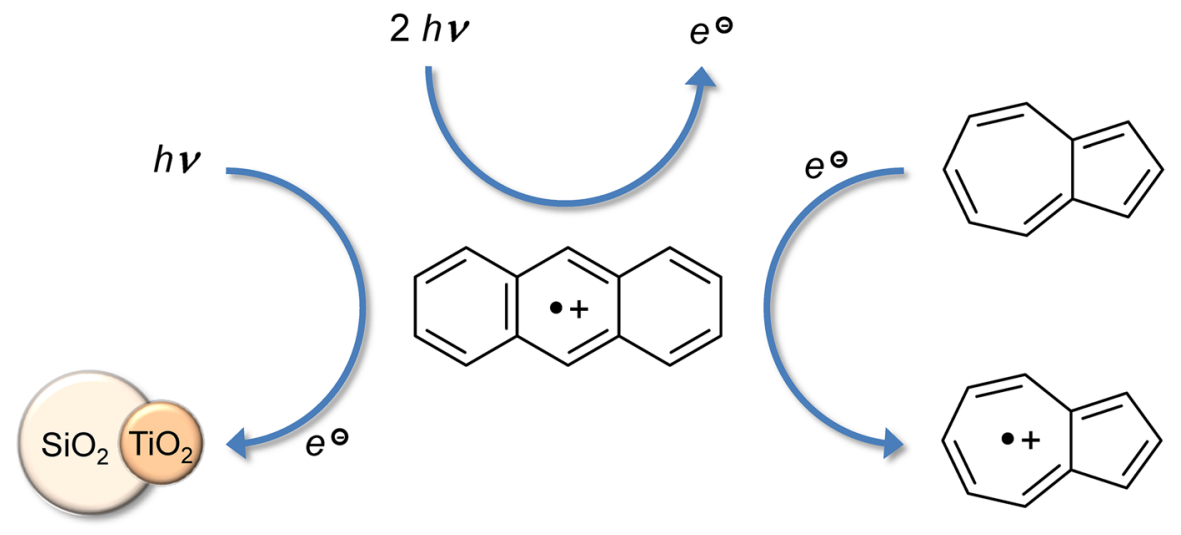

Keywords Silica $\cdot$ Titania $\cdot$ Photocatalysis $\cdot$ Energy/electron transfer $\cdot$ Diffusion

Reflectance

\section{Introduction}

Photochemical processes in heterogeneous systems have large applications in photography, chemical synthesis and the conversion and storage of solar energy. There have been numerous studies of the photochemistry and photophysics of organic molecules adsorbed on oxide surfaces. The surface plays an important role in influencing the course of a photochemical reaction [1-30]; on a non-reactive surface, such as silica gel, energy and/or electron transfer has been demonstrated to occur between adsorbed molecules with little active participation from the surface other than to act to control diffusion. However, on a reactive surface, such as titania or titania-silica mixed oxides the surface can directly interact with the excited states and modify the observed chemistry [10, 25-30]. The mobility of molecules adsorbed on silica gel and also on titania-silica surfaces have been previously reported [11-13, 27-30] and studied through both energy and electron transfer reactions.

Multiphoton ionisation of arenes and the subsequent electron transfer reactions of their radical cations on silica gel have been previously reported $[2-5,8]$. The influence of the nature and loading of the electron donor and electron acceptor compounds on the reaction rates was investigated. The heterogeneous nature of the adsorption sites of solid powdered samples usually implies complex kinetics. The kinetics of decay of radical ions on silica gel and titania-silica surface is not simple since the surface is heterogeneous in nature and rates rarely conform to simple exponential kinetics. We have used the model described by Albery et al. [31] to characterise our data sets [2-6, 13-15], employing a comprehensive exploration of the parameter space in order to obtain a global optimum value for the rate constants 
$[2,3]$. Additionally, we have used Monte-Carlo simulations to model the molecular behaviour and have found good correlations with experiment [15].

Currently, there is a great deal of continued interest in photocatalysis and metal/ mixed oxides are widely used as photocatalytic materials. It is, therefore, important to develop a greater understanding of reactions (photochemical and electrochemical) on these surfaces, to aid the optimisation of these processes and materials [32-35].

The titania anatase phase is known to be a photocatalyst with many applications in the field of environmental protection and energy development [36, 37]. Titania-silica mixed oxides exhibit higher thermal stability, larger surface area and a better photocatalytic performance than pure titania [38-40]. Hence, the photocatalytic activity [41-44] and photoinduced hydrophilic activity [45, 46] can be enhanced when titania is combined with silica. This phenomenon arises through the generation of new active sites due to interactions between titania and silica, giving improved mechanical strength, thermal stability and increased surface area [47, 48] and perhaps to the absence of a rutile phase in the supported oxide samples [49]. The modification of titania with silica and zirconia [35] or alumina [40] has been shown to provide a better photocatalyst for the oxidation of ethylene. The photocatalytic activity is improved relative to $\mathrm{TiO}_{2}$ alone when the mixed oxides (prepared by a sol-gel process) are used in the photocatalytic decomposition of different organic compounds.

The relationships between structural characteristics and reactivity have been previously analysed [50]. The structure and surface properties of titania-silica mixed oxides depend on the method of synthesis and the chemical composition of components. The literature reports several sol-gel methods for preparation of titania-silica mixed oxides, which provides a homogeneous distribution of the components at the atomic level [51, 52]. The use of base- or acid-catalysed hydrolysis of tetraethyl orthosilicate (TEOS) in the preparation of titania-silica materials allows the production of materials that have excellent textural properties with potential for use as a catalytic support. The chemical interaction between the silicon and titanium oxides depends on the degree of dispersion and the thermal treatment. The $-\mathrm{OH}$ groups from the oxide surface are hydrophilic and act as adsorptive/reactive sites. The dispersion capacity depends on the concentration of $-\mathrm{OH}$ groups on the silica surface and the method of preparation.

The aim of this study was to investigate energy and electron transfer processes on silica-titania mixed oxides, over a range of titania content. The findings were compared to those previously obtained on a silica gel surface $[2,3]$.

\section{Experimental}

\section{Silica gel powder}

Commercial porous silica gel (Davisil grade 635, 60-100 mesh, $6 \mathrm{~nm}$ pore size, surface area $480 \mathrm{~m}^{2} \mathrm{~g}^{-1}$ ) was purchased from Sigma-Aldrich. 


\section{Preparation of titania-silica samples}

Titania-silica mixed oxides obtained by the sol-gel method were synthesized according to a technique reported in literature [53, 54]. Titania-silica mixtures with $1,3,5$ and $10 \mathrm{wt} \%$ of $\mathrm{TiO}_{2}$ were prepared from tetraethyl orthosilicate (TEOS; 98\%, Sigma-Aldrich), water, $2 \mathrm{M}$ nitric acid, titanium(IV) isopropoxide (TIP, 97\%, Sigma-Aldrich) and 2-propanol (spectrophotometric grade, Sigma-Aldrich). The molar ratios were: TEOS: $\mathrm{H}_{2} \mathrm{O}: \mathrm{HNO}_{3}: \mathrm{TIP}: 2-$ $\mathrm{PrOH}=1: 20: 1.04: 0.05: 0.2$. $2 \mathrm{M}$ nitric acid was added to deionized water and stirred for a few minutes and then TEOS was added under continuous stirring until the solution became transparent. The mixture was then stirred for a further $30 \mathrm{~min}$ at room temperature. After this time, the solution was stirred continuously while it was heated to $80{ }^{\circ} \mathrm{C}$ and held at these conditions for $30 \mathrm{~min}$ before cooling to room temperature. Next, the TIP solution (a mixture of TIP and 2-propanol) was added dropwise to the silica solution under vigorous stirring. The titania-silica mixed oxides were then heated at $80{ }^{\circ} \mathrm{C}$ for $5 \mathrm{~min}$. The mixture changed slowly from clear to opaque and white, indicating that hydrolysis of the titanium alkoxide had occurred. The solvents formed during the hydrolysis and condensation process were removed by rotary evaporation. The solid was filtered out and washed extensively with distilled water. The washed solid was dried in air for $16 \mathrm{~h}$ at $60{ }^{\circ} \mathrm{C}$ and then at $130{ }^{\circ} \mathrm{C}$ for a further $6 \mathrm{~h}$. The resulting titania-silica solids were calcined at $450{ }^{\circ} \mathrm{C}$ for 30 min to remove residual organics on the surface and to promote formation of the anatase crystalline phase. Finally, titania-silica solids were ground to white fine powders. A large amount of water $(20 \mathrm{~mol})$ results in complete hydrolysis of the alkoxide precursor and it is followed by the condensation process which leads to formation of cross-linked colloidal particles [55]. Also, an increase in the amount of acid leads to a fast gelation time [53].

\section{Preparation of co-adsorbed anthracene and azulene on silica gel and titania- silica mixed oxides}

Silica gel and titania-silica mixed oxides with different titania content were dried at a temperature of $125{ }^{\circ} \mathrm{C}$ under a vacuum of $5 \times 10^{-5}$ mbar for $8 \mathrm{~h}$ to remove physisorbed water. Anthracene (scintillation grade, 99\%, Sigma-Aldrich) and azulene (99\%, Sigma-Aldrich) were dissolved in acetonitrile (spectrophotometric grade, Sigma-Aldrich) and a known weight of the resulting solution was added (under a nitrogen atmosphere) to the dried silica gel and titania-silica surfaces. Anthracene loading was kept constant at $1.0 \mu \mathrm{mol} \mathrm{g}^{-1}$, while the azulene loadings used for preparation of samples were in the range of $0.25-2.0 \mu \mathrm{mol} \mathrm{g}^{-1}$, corresponding to $<5 \%$ (monolayer) coverage. The mixture was allowed to equilibrate for a period of $1 \mathrm{~h}$, with periodic agitation. The solvent was then removed under vacuum and resulting samples of anthracene co-adsorbed with azulene on silica gel or titania-silica surfaces were dried under vacuum to a pressure of $5 \times 10^{-5}$ mbar for a further $8 \mathrm{~h}$ and sealed into a cylindrical glass or quartz cuvette 
(10 mm path length). Sample loadings were determined from the mass of solution and concentration of dissolved compounds added to the surface.

\section{Ground state diffuse reflectance spectra}

Ground state diffuse reflectance measurements were performed using a Perkin-Elmer Lambda Bio 40 spectrophotometer equipped with a Spectralon integrating sphere. The spectra were recorded between 300 and $800 \mathrm{~nm}$ using barium sulphate as reference.

\section{Fluorescence emission spectra}

The fluorescence emission spectra of anthracene co-adsorbed with azulene on silica gel and titania-silica surfaces were recorded using a Spex FluoroMax spectrofluorimeter configured for front face geometry.

\section{Nanosecond diffuse reflectance laser flash photolysis experiments}

The nanosecond diffuse reflectance laser flash photolysis apparatus has been described previously in references $[16,17]$. Diffuse reflectance laser flash photolysis studies were carried out by excitation with the third harmonic (355 nm, $5 \mathrm{~ns}$ fwhm, $110 \mathrm{~mJ} / \mathrm{pulse})$ of a Continuum Surelite I Nd:YAG laser. The pulse energy was attenuated using solutions of sodium nitrite in water, to ensure that transient reflectance changes were kept below $10 \%$, where the change in reflectance is directly proportional to the concentration of transient species [56-58]. Diffusely reflected analysing light from a $300 \mathrm{~W}$ xenon arc lamp (Oriel) was collected and focused onto the entrance slit of a f/3.4 grating monochromator (Applied Photophysics) and detected with a side-on photomultiplier tube (Hamamatsu R928). Signal capture was by a LT364 Waverunner digital oscilloscope (LeCroy).

The solid support can affect or even control the photochemistry and photophysics of an adsorbed probe. The heterogeneous nature of the adsorption sites of solid powdered samples usually leads to complex kinetics.

One of the more successful models for analysing decays of adsorbed molecules on heterogeneous solid supports, in this context, is that developed by Albery et al. [31]. The Albery model accounts for heterogeneous kinetics with two adjustable parameters: an average rate constant $(\bar{k})$ and a parameter determining the width of the rate constant distribution $(\gamma)$, according to Eq. (1):

$$
\frac{C}{C_{0}}=\frac{\int_{-\infty}^{+\infty} \exp \left(-x^{2}\right) \exp [-\bar{k} t \exp (\gamma x)] \mathrm{d} x}{\int_{-\infty}^{+\infty} \exp \left(-x^{2}\right) \mathrm{d} x},
$$

which was transformed to have finite integrals as described in the appendix of reference 31. Here $C$ and $C_{0}$ are transient concentrations at times $t=t$ and $t=0$ after 
laser pulse, $\bar{k}$ represents the mean rate constant and $\gamma$ is the width of the distribution. The replacement of transient concentration $C$ and $C_{0}$ by the reflectance changes at times $t=t$ and $t=0$ (relative to the laser pulse) represented by the symbols $\Delta R$ and $\Delta R_{0}$ can be applied at low sample loadings and reflectance change less than $10 \%$. The transient decays were analysed by fitting for $k$ over a range of $\gamma$ values in order to ensure a global minimum in the reduced Chi square $\left(\chi^{2}\right)$ parameter space [2]. This model is applicable in systems such as these where transient species are either spectrally separated from one another, decay on very different timescales, or where the quantum yields of potentially interfering species are negligible (vide infra). We have established [6] that the fitting parameters are not dependent on the analysing wavelength across the absorption band of the species of interest in these systems [6]. Additionally, we have also successfully applied this model in the analysis of data for termolecular systems $[4,5]$, and hence, the data presented here can be directly compared with our previously published work.

\section{Results and discussion}

\section{BET surface area}

Structural properties of titania-silica mixed oxides calcined in air at $450{ }^{\circ} \mathrm{C}$ are listed in Table 1. As described in the experimental section, a high water/alkoxide ratio of 20:1 was chosen for the hydrolysis precursor of silica. The gel obtained under these conditions is porous with a high surface area. The surface area of titania-silica mixed oxides decrease as the percentage of titania is increased as evident from Table 1. The values presented in this table have been obtained following the method described in the supporting information. The decrease in surface area may be due to the occupation of titania in the pores of the aerogels. For example, Balkis et al. [59] reported that the decrease in surface area with increasing silver content in silver-silica aerogels is attributed to crystallisation of silver particles in the pores of the aerogel matrix.

\section{Ground state diffuse reflectance spectra}

UV spectroscopy has been utilised to characterise the bulk structure of titania-silica mixed oxides. Titania is a semiconductor oxide with an easily measured optical band

Table 1 BET surface areas and pore diameter of titania-silica mixed oxides with different titania content calcined in air at $450{ }^{\circ} \mathrm{C}$

\begin{tabular}{lll}
\hline Sample & $\begin{array}{l}\text { BET surface area } \\
\left(\mathrm{m}^{2} / \mathrm{g}\right)\end{array}$ & Pore diameter $(\mathrm{nm})$ \\
\hline $1 \% \mathrm{TiO}_{2}$ & $727 \pm 2.3$ & $3.8 \pm 0.12$ \\
$3 \% \mathrm{TiO}_{2}$ & $662 \pm 5.1$ & $2.9 \pm 0.22$ \\
$5 \% \mathrm{TiO}_{2}$ & $585 \pm 10.9$ & $2.7 \pm 0.24$ \\
$10 \% \mathrm{TiO}_{2}$ & $619 \pm 7.3$ & $2.8 \pm 0.24$ \\
\hline
\end{tabular}


gap. Ultra-violet diffuse reflectance spectroscopy is used to probe the band structure or molecular energy levels, in the materials since UV excitation creates photogenerated electrons and holes. Spectra of titania-silica mixed oxides prepared by the sol-gel method with different titania content are presented in Fig. 1.

The band gap energy of bulk anatase $[60,61]$ is $3.2 \mathrm{eV}$. The band gaps estimated from the absorption spectra (calculated by extrapolation, which means extending the plotted curve until it intersects the $x$-axis and the value of the intersection point, in $\mathrm{nm}$, is then converted to $\mathrm{eV}$ ) are as follows: $1 \% \mathrm{TiO}_{2}, 4 \mathrm{eV} ; 3 \% \mathrm{TiO}_{2}, 3.8 \mathrm{eV} ; 5 \%$ $\mathrm{TiO}_{2}, 3.7 \mathrm{eV} ; 10 \% \mathrm{TiO}_{2}, 3.4 \mathrm{eV}$. The band gap energy of titania-silica mixed oxides was found to increase with a decrease in the titania content. The shift of the band gap to higher energy might be the result of the quantum size effect. As the titania content of the titania-silica mixed oxides increases, the UV absorption edge shifts to longer wavelengths. This spectral shift may indicate that the Ti domains grow progressively larger with increasing titania content; however, this may also be due to an electronic semiconductor-support interaction which would also act to lower the band gap [9]. Further characterisation would be required to elucidate this exact mechanism.

Figure 2 shows the ground state diffuse reflectance spectra (remission function) of anthracene co-adsorbed with azulene, as a function of azulene loading on a silica gel and titania-silica surface $\left(1 \% \mathrm{TiO}_{2}\right)$. The Kubelka-Munk remission function $F\left(R_{\infty}\right)$ is used to express the linear relationship between concentration and the observed reflectance:

$$
F\left(R_{\infty}\right)=\frac{\left(1-R_{\infty}\right)^{2}}{2 R_{\infty}}=\frac{K}{S}
$$

where $R_{\infty}$ is the observed diffuse reflectance from the surface of a homogeneous optically thick sample, $K$ is the absorption coefficient and $S$ is the scattering coefficient.

Fig. 1 Ground state diffuse reflectance spectra of titaniasilica mixed oxides prepared by the sol-gel method at different titania content

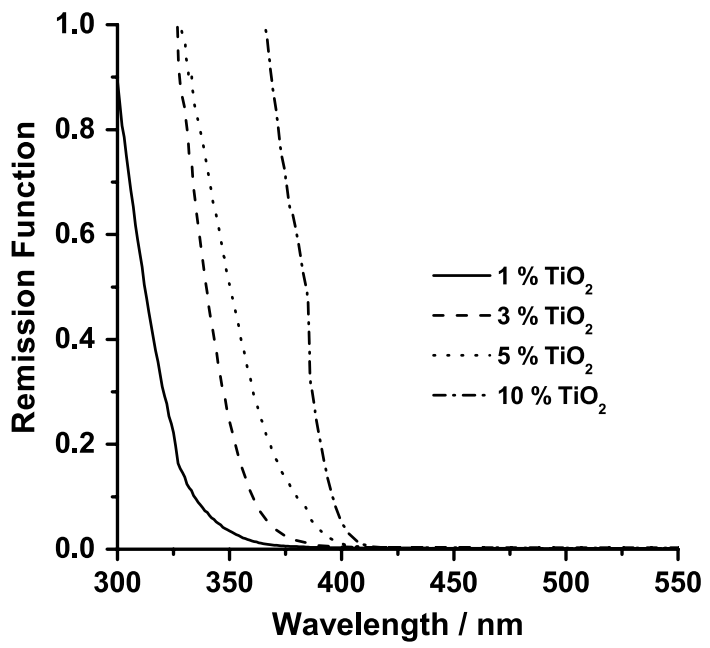


Fig. 2 Ground state diffuse reflectance spectra, plotted as remission function, of anthracene $\left(1.0 \mu \mathrm{mol} \mathrm{g}^{-1}\right)$ co-adsorbed with azulene on: silica gel (solid and dashed lines) and titaniasilica surface at a loading of $1 \%$ $\mathrm{TiO}_{2}$ (dotted and dash dotted lines) as a function of azulene loading

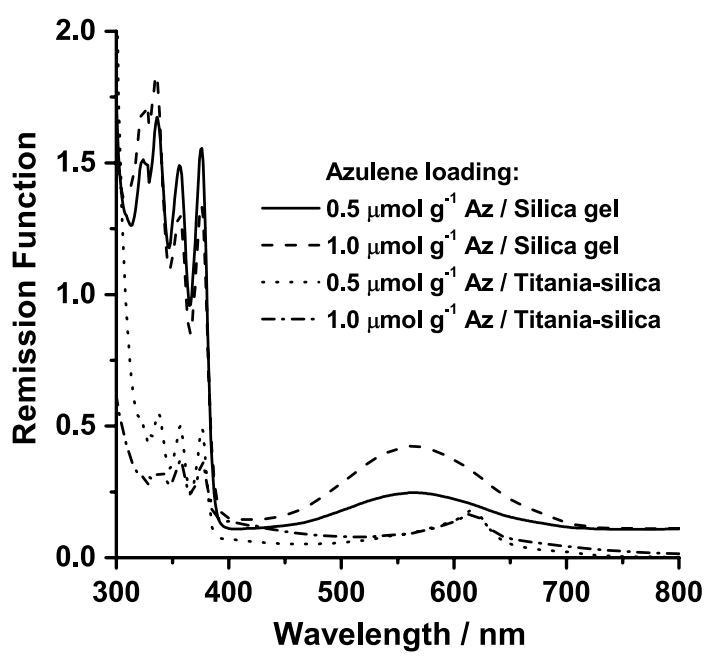

Upon inspection of the reflectance spectra of anthracene/azulene samples, it is clear that the absorption peaks corresponding to anthracene are in the spectral range 330-380 $\mathrm{nm}$. As the azulene loading is increased, the spectra show a broadening as a result of azulene absorbing in the same spectral region as anthracene. The broad bands in the region of 450-700 nm could be attributed to the interaction of the adsorbed molecules with the active sites of the surface and due to the heterogeneous nature of the surface. As shown in Figs. 2 and 3 there is a significant difference in both band shape and absorption maximum with increasing titania loading. In Fig. 2 no bathochromic shift is observed with increasing azulene loading. The consequence of this effect is discussed in detail later when

Fig. 3 Ground state diffuse reflectance spectra, plotted as remission function, of anthracene $\left(1.0 \mu \mathrm{mol} \mathrm{g}^{-1}\right)$ co-adsorbed with azulene $\left(1.0 \mu \mathrm{mol} \mathrm{g}^{-1}\right)$ on titania-silica surfaces as a function of titania content. The inset shows an expansion of the spectral region between 660 and $780 \mathrm{~nm}$

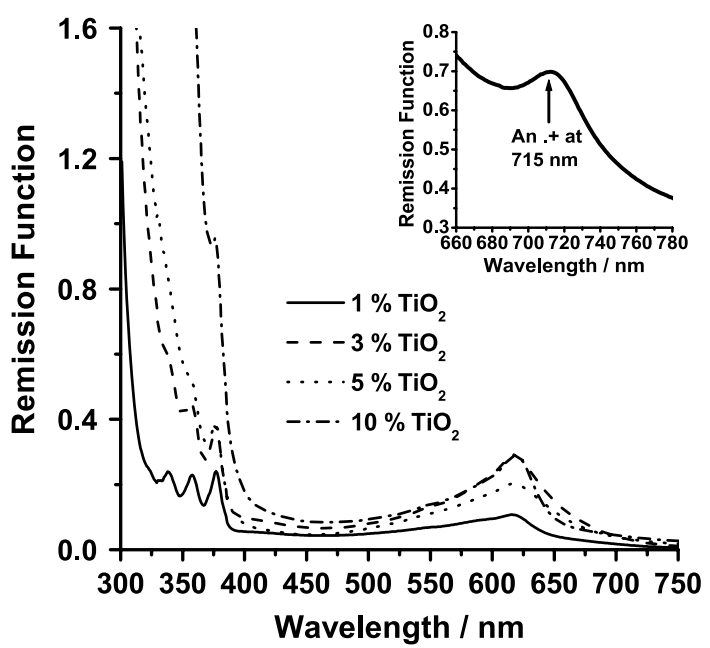


addressing the determination of rate constants (vide infra). Also, a deviation from Kubelka-Munk theory can be observed. This can be explained by formation of aggregates which cause a reduction in the expected absorption. This effect has been observed previously on a silica gel surface [7].

The absorption peaks of anthracene are difficult to observe when the titania content is high due to a significant overlap of the titania absorption edge with the anthracene absorption as the band gap decreases (Fig. 3). The absorption peak corresponding to the anthracene radical cation can be observed at $715 \mathrm{~nm}$. This small amount of anthracene radical cation is formed after irradiation of the samples with the UV lamp (a low intensity light source) of the spectrophotometer. This means the production of the anthracene radical cation under these conditions is a monophotonic process $[27,60,61]$. A blank experiment was performed on a sample containing just azulene and no transient absorption or radical cation formation was observed.

The formation of an anthracene radical cation on a titania-silica surface is attributed to the interactions of anthracene with Lewis acid sites present on the surface i.e. charge transfer from the anthracene singlet excited state into the conduction band of titania [62]. This is assigned on the basis that on a silica gel surface mono-photonic ionisation does not occur.

A simplified representation of deactivation pathways of anthracene coadsorbed with azulene on titania-silica surface when excited at $355 \mathrm{~nm}$ is shown below in Table 2 (here $\mathrm{D}$ denotes electron donor, i.e. azulene).

Table 2 Deactivation pathways of anthracene co-adsorbed with azulene on titania-silica surface

\begin{tabular}{|c|c|c|}
\hline $\mathrm{An}+h \nu \rightarrow \mathrm{An}^{*}\left(\mathrm{~S}_{1}\right)$ & Excitation & $\mathrm{i}$ \\
\hline $\mathrm{An}^{*}\left(\mathrm{~S}_{1}\right)+h \nu \rightarrow \mathrm{An}^{+}+\mathrm{e}^{-}$ & Ionisation & ii \\
\hline $\mathrm{An}^{*}\left(\mathrm{~S}_{1}\right) \stackrel{k_{\mathrm{f}}}{\longrightarrow} \mathrm{An}\left(\mathrm{S}_{0}\right)+h v_{\mathrm{f}}$ & Fluorescence & iii \\
\hline $\mathrm{An}^{*}\left(\mathrm{~S}_{1}\right) \stackrel{k_{\mathrm{ic}}}{\longrightarrow} \mathrm{An}\left(\mathrm{S}_{0}\right)+$ heat & Internal conversion & iv \\
\hline $\mathrm{An}^{*}\left(\mathrm{~S}_{1}\right)^{3} \stackrel{k_{\mathrm{isc}}}{\longrightarrow}{ }^{3} \mathrm{An}\left(\mathrm{T}_{1}\right)$ & Intersystem crossing & $\mathrm{v}$ \\
\hline${ }^{3} \mathrm{An}\left(\mathrm{T}_{1}\right) \stackrel{k_{\mathrm{p}}}{\longrightarrow} \mathrm{An}\left(\mathrm{S}_{0}\right)+h v_{\mathrm{p}}$ & Phosphorescence & vi \\
\hline $\mathrm{D}+n h \nu \rightarrow \mathrm{D}^{+}+\mathrm{e}^{-}$ & Photoionisation of electron donor & vii \\
\hline $\mathrm{An}^{+}+\mathrm{D} \rightarrow \mathrm{An}+\mathrm{D}^{+}$ & Electron transfer & viii \\
\hline $\mathrm{An}^{+}+\mathrm{e}^{-} \rightarrow \mathrm{An}$ & Ion-electron combination & ix \\
\hline$A n^{*}\left(S_{1}\right)+A n \rightarrow[A n \cdots A n]^{*}$ & Excimer formation & $\mathrm{x}$ \\
\hline$[\mathrm{An} \cdots \mathrm{An}]^{*} \rightarrow \mathrm{An}+\mathrm{An}+h \nu$ & Excimer emission & xi \\
\hline $\mathrm{An}^{*}\left(\mathrm{~S}_{1}\right)+\mathrm{D} \rightarrow[\mathrm{An} \cdots \mathrm{D}]^{*}$ & Exciplex formation & xii \\
\hline $\mathrm{TiO}_{2}+h \nu \rightarrow \mathrm{TiO}_{2}\left(\mathrm{e}_{\mathrm{CB}}^{-}\right)+h_{\mathrm{VB}}^{+} \mathrm{e}_{\mathrm{CB}}^{-} \rightarrow \mathrm{e}_{\mathrm{t}}^{-}$ & $\begin{array}{l}\text { Localized electron trapped on the surface of } \\
\mathrm{TiO}_{2}\end{array}$ & xiii \\
\hline $\mathrm{An}^{*}+\mathrm{TiO}_{2} \rightarrow \mathrm{An} \cdots \mathrm{TiO}_{2} \rightarrow \mathrm{Ti}^{3+}$ & Charge transfer from An to $\mathrm{TiO}_{2}$ & xiv \\
\hline $\mathrm{An}^{*}\left(\mathrm{~S}_{1}\right)+\mathrm{TiO}_{2} \rightarrow \mathrm{An}^{+}+\mathrm{TiO}_{2}\left(\mathrm{e}_{\mathrm{CB}}^{-}\right)$ & $\begin{array}{l}\text { Charge transfer from the excited state An into } \\
\text { the } \mathrm{CB} \text { of } \mathrm{TiO}_{2}\end{array}$ & $\mathrm{XV}$ \\
\hline
\end{tabular}


Fig. 4 Fluorescence emission spectra of anthracene $\left(1.0 \mu \mathrm{mol} \mathrm{g}{ }^{-1}\right)$ co-adsorbed with azulene on silica gel, following excitation at $355 \mathrm{~nm}$, plotted as a function of azulene loading

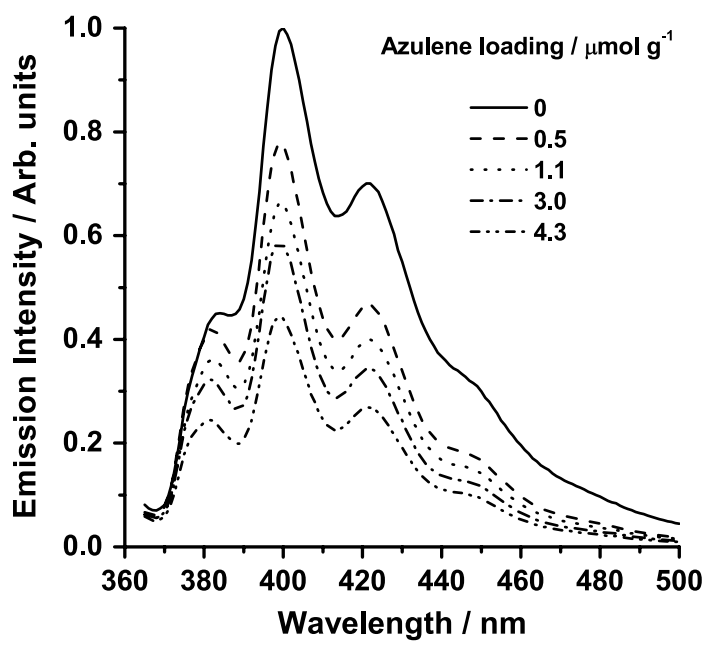

\section{Fluorescence emission spectra}

Fluorescence emission spectra of anthracene co-adsorbed with azulene on silica gel and titania-silica surfaces were measured following excitation at $355 \mathrm{~nm}$. Figure 4 shows spectra measured for anthracene $\left(1.0 \mu \mathrm{mol} \mathrm{g}^{-1}\right)$ co-adsorbed with various azulene loadings. The fluorescence emission spectra confirm the presence of the peaks corresponding to the anthracene molecule at $385 \mathrm{~nm}, 400 \mathrm{~nm}$, $426 \mathrm{~nm}$ and a small, poorly resolved peak at $450 \mathrm{~nm}$.

Co-adsorption of azulene on silica gel and titania-silica mixed oxides resulted in a decrease in the fluorescence intensity of the adsorbed anthracene; the emission intensity of anthracene decreases with increasing azulene loading.

Fig. 5 Fluorescence emission spectra of anthracene $\left(1.0 \mu \mathrm{mol} \mathrm{g}{ }^{-1}\right)$ co-adsorbed with azulene $\left(1.0 \mu \mathrm{mol} \mathrm{g}{ }^{-1}\right)$ on titania-silica surfaces, following excitation at $355 \mathrm{~nm}$, plotted as a function of titania loading

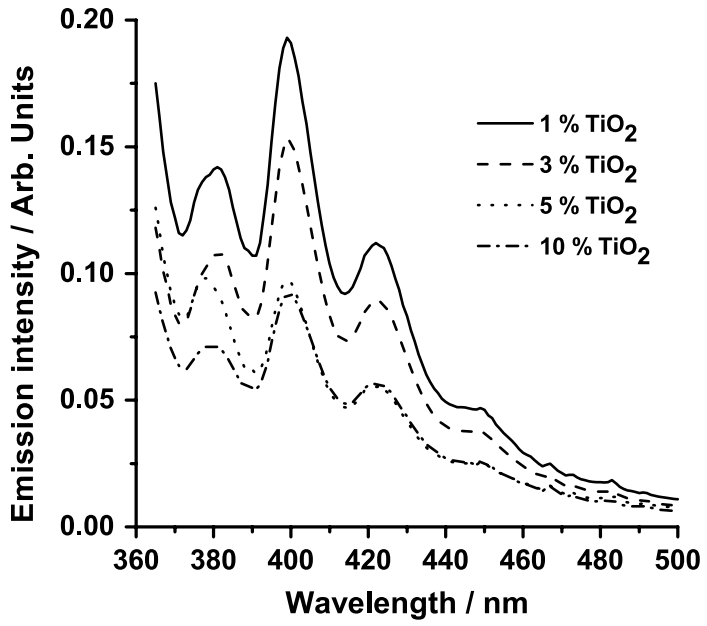


The absence of any spectral shift with change in azulene loading leads us to conclude that the emission is primarily from the anthracene $S_{1}$ state.

A large decrease in fluorescence intensity can be observed for samples adsorbed on titania-silica surface (Fig. 5) compared with samples prepared on silica gel. This reduction in fluorescence intensity can be attributed to production of anthracene radical cation and $\mathrm{Ti}^{3+}$ (excitation of the samples with $355 \mathrm{~nm}$ UV radiation produces both anthracene radical cation and $\mathrm{Ti}^{3+}$ ). The anthracene singlet excited state is quenched by interaction with titania sites. The formation of $\mathrm{Ti}^{3+}$ species causes a complex decay of the anthracene excited state. Alternatively, the sol gel samples contain tetrahedrally coordinated titanium dioxide species which possess high adsorption activity and hence dimer formation could be considered as a mechanism for fluorescence quenching [63].

Quenching of the anthracene fluorescence by azulene occurs in both systems (silica gel and titania-silica mixed oxides) contributing to the reduction in fluorescence emission intensity of anthracene. Emission from the anthracene/azulene exciplex has been detected previously on silica gel [2], but unfortunately such measurements were not available for this system.

The fluorescence emission intensity of adsorbed anthracene decreases with increasing titania content (Fig. 5). The observed fluorescence is from anthracene molecules adsorbed on silica sites, while enhanced quenching is observed at low anthracene loading $\left(1.0 \mu \mathrm{mol} \mathrm{g}{ }^{-1}\right)$ via an electron transfer mechanism which occurs between the anthracene excited singlet state and titania centres suggesting preferential adsorption of anthracene molecules at titania sites. If the anthracene was purely statistically distributed on the surface, the titania sites would not be expected to have such a profound effect on the emission intensity. Another mechanism responsible for the observed decrease in the fluorescence intensity is the inner filter effect in the region of the spectra where there is overlap between the anthracene absorption and titania absorption edge, as is clearly evident in Fig. 3.

The singlet excited state of anthracene may undergo fluorescence and intersystem crossing. The triplet excited state of anthracene interacts with azulene present in the system by energy transfer or by molecular aggregation [64, 65], with exciplex formation occurring in the latter case $[2,13]$.

\section{Transient absorption spectra}

Transient absorption spectra of the anthracene/azulene systems were obtained after $355 \mathrm{~nm}$ laser excitation of the respective samples as shown in Fig. 6. This figure reveals the presence of two species: the anthracene excited triplet state at $420 \mathrm{~nm}$ and anthracene radical cation located at $715 \mathrm{~nm}$. These absorption bands were assigned based upon previous measurements $[2,3,7,8]$.

When comparing the spectra of anthracene co-adsorbed with azulene on silica gel and on titania-silica mixed oxides, some differences can be observed in the relative intensities of the triplet state and radical cation bands. The anthracene radical cation absorption is significantly higher for anthracene samples on titania-silica systems compared to that of an anthracene sample prepared on silica 
Fig. 6 Transient absorption spectrum of anthracene $\left(1.0 \mu \mathrm{mol} \mathrm{g}{ }^{-1}\right)$ co-adsorbed with azulene $\left(1.0 \mu \mathrm{mol} \mathrm{g}^{-1}\right)$ on: silica gel (solid line) and titaniasilica surface at a loading of $1 \%$ $\mathrm{TiO}_{2}$ (dashed and dotted lines) following laser excitation at $355 \mathrm{~nm}$

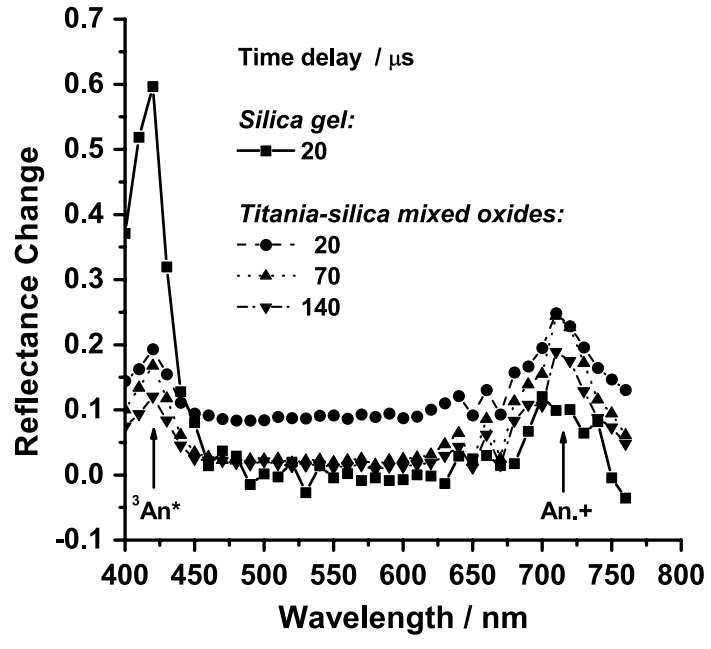

gel. An increased yield of anthracene radical cation could be attributed to the electron transfer process from excited singlet state anthracene to the $\mathrm{TiO}_{2}$ sites of the titania-silica mixed oxides, giving rise to anthracene radical cation and $\mathrm{Ti}^{3+}$ species. Further evidence for this process is seen in a significant reduction of anthracene triplet state absorption on the silica-titania surface, through quenching of the anthracene singlet state. The singlet state otherwise undergoes intersystem crossing, in the absence of a quencher such as titania. Moreover, we have observed a slight decrease in anthracene triplet-triplet absorption and anthracene radical cation absorption intensities as the content of titania is increased (Fig. 7). The decays of both anthracene triplet state and anthracene radical cation are slower for samples containing a higher amount of titania. This observation is also

Fig. 7 Transient absorption spectrum of anthracene $\left(1.0 \mu \mathrm{mol} \mathrm{g}{ }^{-1}\right)$ co-adsorbed with azulene $\left(1.0 \mu \mathrm{mol} \mathrm{g}{ }^{-1}\right)$ on titania-silica surface at a loading of $1 \% \mathrm{TiO}_{2}$ (solid line) and $5 \% \mathrm{TiO}_{2}$ (dashed and dotted lines) following laser excitation at $355 \mathrm{~nm}$

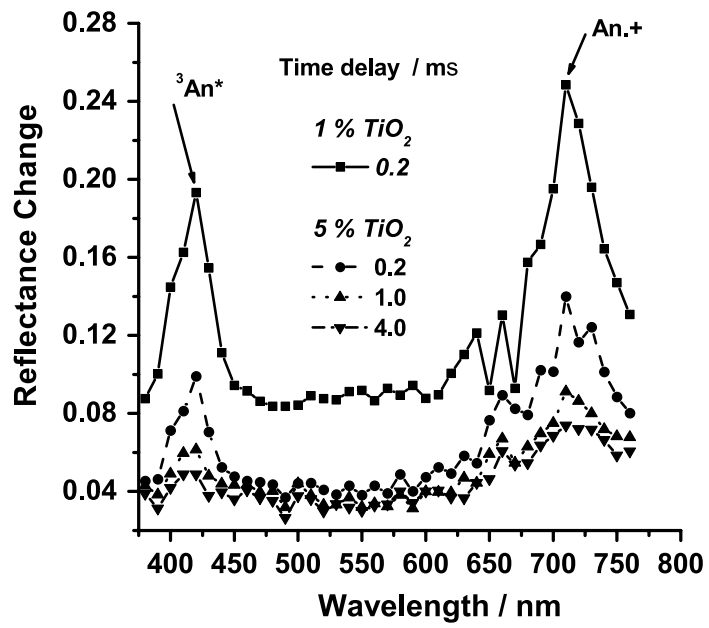

Springer 
reflected in the rate constants of anthracene triplet state and radical cation decays; the rate constants for both transients decrease with increasing titania content.

Transient absorption in the titania-silica samples may be attributed [27] to production of the anthracene radical cation and to the photoinduced production of trapped electrons $\left(\mathrm{Ti}^{3+}\right)$ which absorb in the region of 580-630 nm.

The spectral characteristics of the transient absorption spectra are not dependent on the azulene loading; however, both anthracene excited triplet state and radical cation have an increased rate of decay when azulene is present and acting as an energy/electron donor. Previously, we have electrochemically measured the oxidation potentials for anthracenes and azulene as $1.26 \mathrm{~V}$ and $1.04 \mathrm{~V}$, respectively (vs. $\mathrm{Ag} / \mathrm{AgCl}$ ) [3]. An increase in azulene loading enhances the rate of decay of transient species. Triplet-triplet energy transfer between anthracene $\left(E_{\mathrm{T}}=178 \mathrm{~kJ} \mathrm{~mol}^{-1}\right)$ and azulene $\left(E_{\mathrm{T}}=163 \mathrm{~kJ} \mathrm{~mol}^{-1}\right)$ is responsible for the increased rate of decay of the anthracene triplet [66]. The azulene triplet state at $368 \mathrm{~nm}$ (in solution [67]) is not observed as a result of its low molar absorption coefficient $\left(4000 \mathrm{dm}^{3} \mathrm{~mol}^{-1} \mathrm{~cm}^{-1}\right)$ and due to overlap with the anthracene triplet band as reported previously in Ref. [8].

In a previous publication [7] we reported the monophotonic production of anthracene excited triplet state and the multiphotonic formation of the anthracene radical cation on silica gel. In the mixed titania-silica systems, laser energy dependence studies confirm the monophotonic nature of anthracene triplet state formation, whereas the anthracene radical cation is formed through a combination of monophoton and bi- or multiphoton ionisation [68]. In the latter case, the formation of the anthracene radical cation on titania-silica mixed oxides is due to electron injection from anthracene excited singlet state to the conduction band of titania particles in the silica matrix.

\section{Kinetics of energy and electron transfer}

The kinetics of the excited triplet state and radical cation of anthracene have been studied following $355 \mathrm{~nm}$ laser excitation, in both the presence and absence of azulene. Anthracene triplet state decay was monitored at $420 \mathrm{~nm}$, while electron transfer between the anthracene radical cation and azulene was monitored at $715 \mathrm{~nm}$, where interference from anthracene triplet state absorption is absent.

Transient decays were analysed as described in previous publications [2, 3] using the dispersive kinetic model of Albery et al. [31]. A typical kinetic trace for the decay of the anthracene radical cation at $715 \mathrm{~nm}$, analysed using the Albery model, is shown in Fig. 8.

Co-adsorption of azulene into anthracene/silica gel or anthracene/titania-silica systems changes the observed energy and electron transfer kinetics. Decay rate constants for both anthracene triplet state and radical cation show a dependence on the titania content and the azulene loading; faster with increasing azulene loading and slower as the titania content is increased (Fig. 9).

We were able to extract mean values for the decay rate constant $\bar{k}$ and by application of Eq. 3, we can obtain a bimolecular rate constant: 
Fig. 8 Radical cation decay measured at $715 \mathrm{~nm}$ of anthracene $\left(1.0 \mu \mathrm{mol} \mathrm{g}^{-1}\right)$ co-adsorbed with azulene $\left(2.0 \mu \mathrm{mol} \mathrm{g}{ }^{-1}\right)$ on titania-silica surface at a loading of $1 \% \mathrm{TiO}_{2}$ following laser excitation at $355 \mathrm{~nm}$ plotted as reflectance change versus time. Fitting by the Albery dispersive kinetic model yields $k=12 \times 10^{3} \mathrm{~s}^{-1}$ and $\gamma=2.4$ corresponding to a global minimum in reduced $\chi^{2}$. Residuals of the fit are shown in inset above
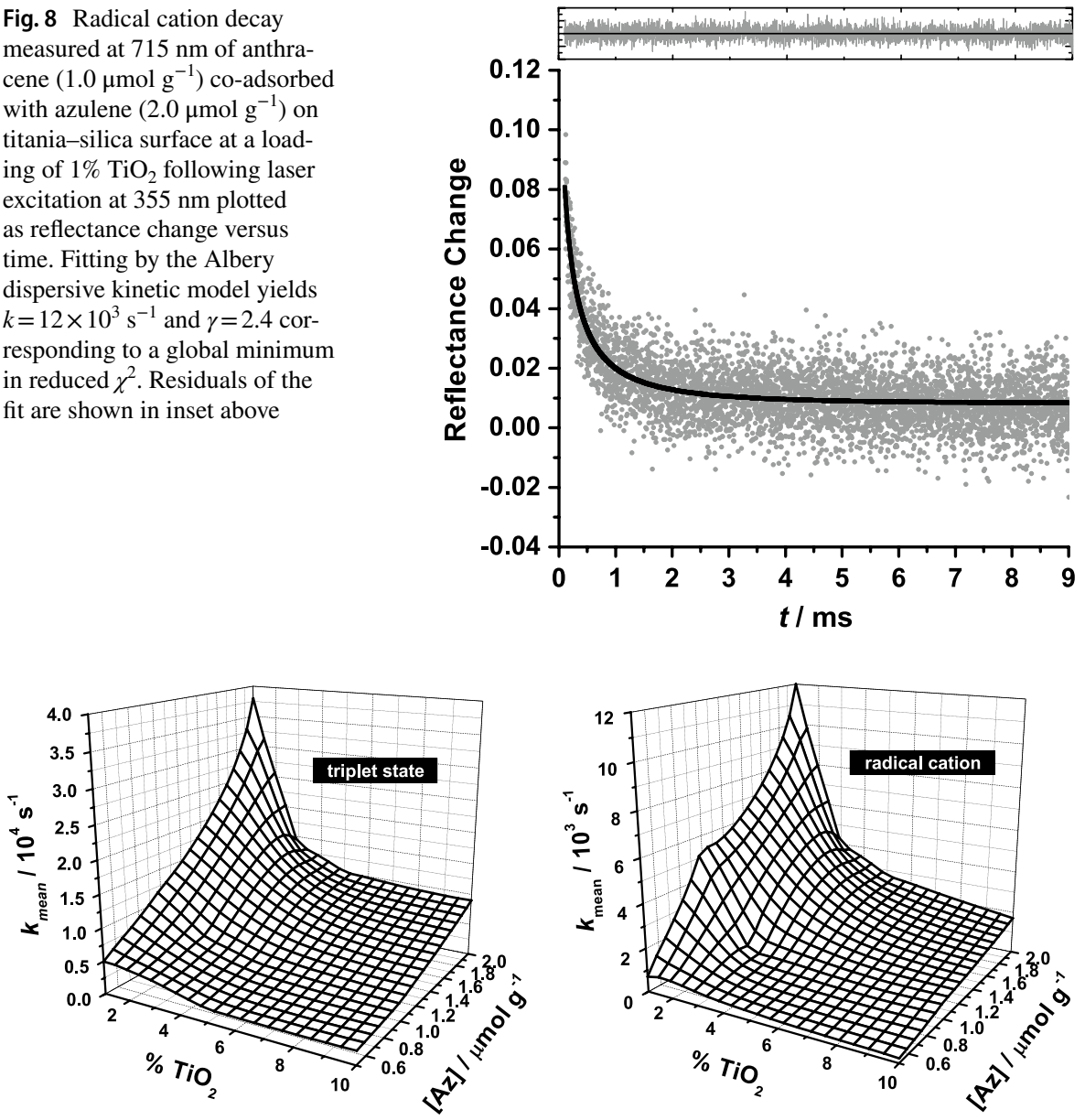

Fig. 9 Variation of the mean rate constants for anthracene $\left(1.0 \mu \mathrm{mol} \mathrm{g}{ }^{-1}\right)$ adsorbed on titania-silica surface plotted as a function of azulene loading and titania content

$$
\bar{k}=k_{0}+k_{q}^{\prime}[Q]
$$

where $\bar{k}$ is the observed rate constant for the anthracene triplet state or radical cation decay in the presence of azulene, $\bar{k}_{0}$ represents the rate of decay of the anthracene triplet state or radical cation in the absence of azulene, $[Q]$ is the concentration of the quenching species (in this case, azulene) and $k_{q}^{\prime}$ is the bimolecular rate constant for the quenching process.

In the analysis of the energy and electron transfer data for anthracene co-adsorbed with azulene on silica gel and titania-silica surfaces it was necessary for the experimental data to be corrected in order to take account of the ground state association between anthracene and azulene, which is indicated in the reflectance spectra (vide supra). A detailed account of our methodology has been published previously [2] 

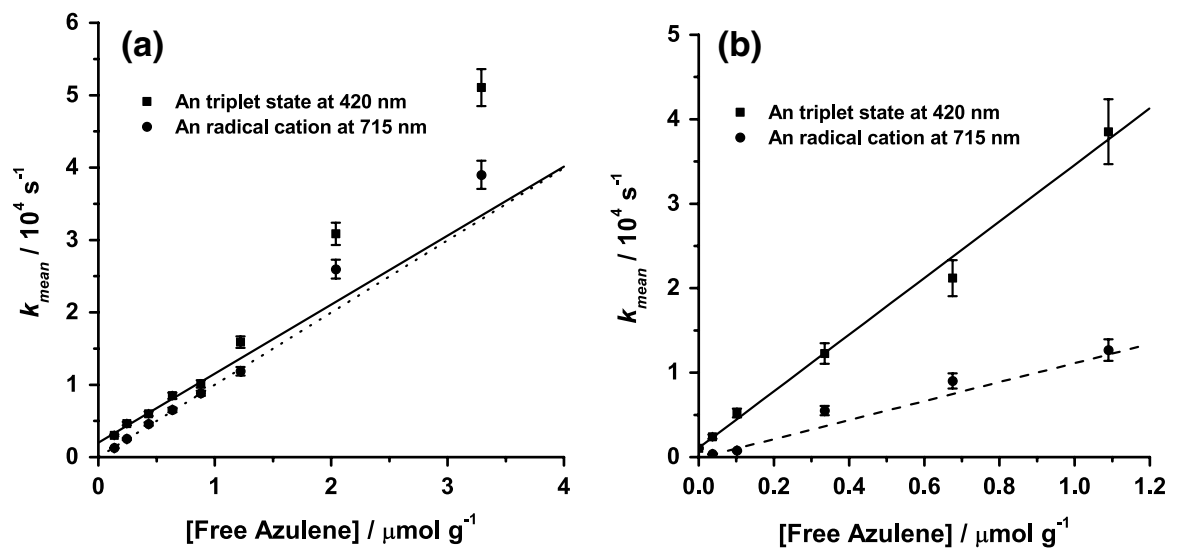

Fig. 10 Plots of the mean rate constant, obtained from the dispersive kinetic analysis for the triplettriplet energy transfer (solid line) and electron transfer (dash line) for anthracene $\left(1.0 \mu \mathrm{mol} \mathrm{g}^{-1}\right)$ coadsorbed with azulene on: a silica gel [2] and $\mathbf{b}$ titania-silica surface at a loading of $1 \% \mathrm{TiO}_{2}$ versus azulene concentration

Table 3 Bimolecular rate constants of anthracene $\left(1.0 \mu \mathrm{mol} \mathrm{g}{ }^{-1}\right)$ co-adsorbed with varying loading of azulene on silica gel and titania-silica surfaces at different titania content

\begin{tabular}{lll}
\hline $\mathrm{TiO}_{2}$ content & \multicolumn{2}{l}{ Anthracene/azulene samples } \\
\cline { 2 - 3 } & $\begin{array}{l}\text { Triplet state quenching constant }\left(\mathrm{g} \mathrm{mol}^{-1}\right. \\
\left.\mathrm{s}^{-1}\right)(\text { energy transfer })\end{array}$ & $\begin{array}{l}\text { Radical cation quenching constant } \\
\left(\mathrm{g} \mathrm{mol}^{-1} \mathrm{~s}^{-1}\right) \text { (electron transfer) }\end{array}$ \\
\hline $1 \% \mathrm{TiO}_{2}$ & $3.4 \pm 0.4 \times 10^{10}$ & $1.2 \pm 0.4 \times 10^{10}$ \\
$3 \% \mathrm{TiO}_{2}$ & $7.4 \pm 0.6 \times 10^{9}$ & $3.1 \pm 0.3 \times 10^{9}$ \\
$5 \% \mathrm{TiO}_{2}$ & $7.8 \pm 0.6 \times 10^{9}$ & $2.3 \pm 0.2 \times 10^{9}$ \\
$10 \% \mathrm{TiO}_{2}$ & $6.7 \pm 0.5 \times 10^{9}$ & $1.6 \pm 0.7 \times 10^{9}$ \\
$\mathrm{Silica}$ gel & $9.5 \pm 0.3 \times 10^{9}$ & $10.0 \pm 0.4 \times 10^{9}$ \\
\hline
\end{tabular}

where we present evidence for the formation of anthracene-azulene association on the basis of exciplex formation as shown by transient emission spectra and static fluorescence quenching [2]. This correction was necessary since the aggregates are relatively immobile and do not contribute to the dynamic quenching process. An association constant, $K=7 \times 10^{6} \mathrm{~g} \mathrm{~mol}^{-1}$ was applied by fitting to the equation in reference 2 . This value was consistent with that obtained previously on a silica gel surface [2] $\left(K=3.6 \times 10^{6} \mathrm{~g} \mathrm{~mol}^{-1}\right)$ and was used to correct the azulene loadings to reflect the proportion which exists in the 'free' form. We have applied this corrected value for the azulene loading to both the anthracene triplet state and radical cation kinetic analysis using Eq. 3.

Figure 10 shows a plot of $\bar{k}$ versus free azulene loading for the anthracene triplet state and anthracene radical cation on silica gel and titania-silica $\left(1 \% \mathrm{TiO}_{2}\right)$ surface and a summary of bimolecular rate constants for energy and electron transfer are provided in Table 3. 
An overall trend in the variation of bimolecular rate constants with titania content was observed. The quenching rate constant was found to decrease with increasing titania content. As can clearly be seen from Fig. 10, the bimolecular rate constants for energy and electron transfer on $1 \%$ titania-silica surface yield different values (the rate of energy transfer is higher than the rate of electron transfer), which indicates that the rate of reaction is governed by the diffusion of anthracene on the surface of titania-silica mixed oxides. This is in contrast to data obtained on silica gel, where $k_{q}^{\prime}$ values for energy and electron transfer of anthracene/azulene samples were found to be the same within the reported error (Table 3), demonstrating that the rate of energy and electron transfer reactions on silica gel are governed by the rate of diffusion of azulene [2, 3].

On the basis that the radical cation is less mobile than the neutral species, in line with observations on silica gel [2,3], this would suggest that diffusion of anthracene is rate limiting in this system.

Azulene is a non-benzenoid aromatic compound possessing $10 \pi$ electrons and may be regarded as a combination of an aromatic negatively charged five-membered and a positively charged seven-membered ring that both formally obey Hückel's $4 n+2$ rule. The charge separation of the zwitterionic form can be considered as the reason for the relatively large dipole moment $[69,70]$. When electron-donating groups, such as - $\mathrm{OH}$ (from the titania-silica surface) are attached to the five-membered ring of azulene, the HOMO and LUMO energy levels increase as a result of increasing electron density in the aromatic ring [71]. If indeed the charge separation of the azulene molecule is responsible for an interaction with $\mathrm{Ti}^{4+}$ sites, thereby binding or restricting mobility, it would be interesting to compare rates of energy and electron transfer using naphthalene as the energy acceptor/electron donor since it is isoelectronic with azulene, but with no net dipole (c.f. $1.08 \mathrm{D}$ for azulene). We have previously studied energy and electron transfer to naphthalene using phenanthrene, for example, as the initially excited/charged species on silica gel. One of our aims for future studies is to measure rate constants for energy and electron transfer, in this or similar systems, on silica-titania mixed oxides. This would allow us to unambiguously determine if anthracene diffusion is rate limiting when titania active sites are present on these surfaces.

\section{Conclusions}

Photophysical and photochemical studies of anthracene co-adsorbed with azulene on silica gel and titania-silica mixed oxide surfaces (prepared by the sol-gel method) have demonstrated that the interaction between the surface and adsorbed molecule, and their mobility, depend on the properties of the solid surface and on the method of oxide synthesis. Quenching of anthracene fluorescence by azulene and also by the titania for samples prepared on titania-silica surfaces was clearly evident. The data show that anthracene has to adsorb in close proximity to the $\mathrm{TiO}_{2}$ sites on the $\mathrm{SiO}_{2}$ matrix. This leads to some quenching of the anthracene fluorescence by the $\mathrm{TiO}_{2}$, but more so by the $\mathrm{Ti}^{3+}$ centres, which are located in the titania chains. Anthracene triplet state formation was found to be monophotonic, whereas the anthracene 
radical cation is formed by both monophoton and multiphoton ionisation in the mixed titania-silica systems.

Energy and electron transfer kinetics have been measured for anthracene on silica gel and titania-silica mixed oxides co-adsorbed with azulene acting as an energy acceptor/electron donor. A linear correlation between the decay rates obtained from the dispersive kinetic model and azulene loading was observed. The rate of energy and electron quenching is seen to decrease with increasing titania content in titania-silica mixed oxides and increase as a function of azulene loading. We have previously shown that the rate of energy and/or electron transfer between anthracene and azulene on a silica gel surface is predominantly governed by the diffusion of the azulene molecule. In contrast, the triplet-triplet energy transfer rate on titania-silica surfaces is faster than the rate of electron transfer between anthracene radical cation and azulene. These results indicate that the rate of these processes on titania-silica mixed oxides is governed by the rate of diffusion of anthracene (either triplet or radical) on the surface. We propose that the charge separation in the azulene molecule facilitates interactions with the $\mathrm{Ti}^{4+}$ sites, thus reducing its mobility relative to that observed on silica gel.

Acknowledgements The authors would like to thank EPSRC for funding this project.

Open Access This article is distributed under the terms of the Creative Commons Attribution 4.0 International License (http://creativecommons.org/licenses/by/4.0/), which permits unrestricted use, distribution, and reproduction in any medium, provided you give appropriate credit to the original author(s) and the source, provide a link to the Creative Commons license, and indicate if changes were made.

\section{References}

1. J.K. Thomas, E.H. Ellison, Adv. Colloid Interface Sci. 89-90, 195 (2001)

2. D.R. Worrall, I. Kirkpatrick, S.L. Williams, Photochem. Photobiol. Sci. 1, 896 (2002)

3. D.R. Worrall, I. Kirkpatrick, S.L. Williams, Photochem. Photobiol. Sci. 3, 63 (2004)

4. S.L. Williams, I. Kirkpatrick, D.R. Worrall, Photochem. Photobiol. Sci. 9, 937 (2010)

5. S.L. Williams, D.R. Worrall, I. Kirkpatrick, A. Vancea, J. Pan, Photochem. Photobiol. Sci. 10, 84 (2011)

6. I. Kirkpatrick, D.R. Worrall, S.L. Williams, C.J.T. Buck, R.G. Meseguer, Photochem. Photobiol. Sci. 11, 1585 (2012)

7. F. Wilkinson, D.R. Worrall, S.L. Williams, J. Phys. Chem. 99, 6689 (1995)

8. D.R. Worrall, S.L. Williams, F. Wilkinson, J. Phys. Chem. B 101, 4709 (1997)

9. H. Weiss, A. Fernandez, H. Kisch, Angew. Chem. Int. Ed. 40, 3825 (2001)

10. H. Kisch, Acc. Chem. Res. 50, 1002 (2017)

11. G.J. Kavarnos, N.J. Turro, Chem. Rev. 86, 401 (1986)

12. A. Liu, M.C. Sauer, D.M. Loffredo, A.D. Trifunac, J. Photochem. Photobiol. A 67, 197 (1992)

13. D.R. Worrall, S.L. Williams, F. Wilkinson, J. Phys. Chem. A 102, 5484 (1998)

14. D.R. Worrall, S.L. Williams, F. Wilkinson, J.E. Crossley, H. Bouas-Laurent, J.P. Desvergne, J. Phys. Chem. B 103, 9255 (1999)

15. D.R. Worrall, S.L. Williams, T. Ganguly, Photochem. Photobiol. Sci. 5, 844 (2006)

16. D.R. Worrall, S. L. Williams, in Encyclopedia of Modern Optics, vol. 1, ed. by R.D. Guenther, D.G. Steel, L. Bayvel (Elsevier, Oxford, 2004), p. 31

17. F. Wilkinson, R. Beer, in Photochemical Processes in Organised Molecular Systems, ed. by K. Honda (Elseveir, Amsterdam, 1991), pp. 377-398 
18. G.H. Zhang, J.K. Thomas, A. Eremenko, T. Kikteva, F. Wilkinson, J. Phys. Chem. B 101, 8569 (1997)

19. D. Oelkrug, M. Gregor, S. Reich, Photochem. Photobiol. 54, 539 (1991)

20. R. Krasnansky, K. Koike, J.K. Thomas, J. Phys. Chem. 94, 4521 (1990)

21. S.A. Ruetten, J.K. Thomas, J. Phys. Chem. B 102, 598 (1998)

22. R. Dabestani, J. Higgin, D. Stephenson, I.N. Ivanov, M.E. Sigman, J. Phys. Chem. B 104, 10235 (2000)

23. R. Dabestani, M. Kidder, A.C. Buchanan, J. Phys. Chem. C 112, 11468 (2008)

24. J.M. Stokke, D.W. Mazyck, Environ. Sci. Technol. 42, 3808 (2008)

25. H. Jafari, S. Afshar, O. Zabihi et al., Res. Chem. Intermed. 42, 2963 (2016)

26. Y. Yang, H. Zhong, C. Tia, Res. Chem. Intermed. 37, 91 (2011)

27. D.R. Worrall, S.L. Williams, A. Eremenko, N. Smirnova, O. Yakimenko, G. Starukh, Colloids Surf. A Physicochem. Eng. Asp. 230, 45 (2004)

28. S.A. Ruetten, J.K. Thomas, Photochem. Photobiol. Sci. 2, 1018 (2003)

29. A. Eremenko, N. Smirnova, O. Yakimenko, G. Starukh, D.R. Worrall, S.L. Williams, Int. J. Photoenergy 06, 11 (2004)

30. A. Eremenko, N. Smirnova, G. Starukh, A. Chuiko, K. Rotkiewicz, A. Danel, J. Photochem. Photobiol. A Chem. 177, 83 (2006)

31. W.J. Albery, P.N. Bartlett, C.P. Wilde, J.R. Darwent, J. Am. Chem. Soc. 107(7), 1854 (1985)

32. J.B. Miller, S.T. Johnston, E.I. Ko, J. Catal. 150, 311 (1994)

33. K.L. Walther, A. Wokaun, B.E. Handy, A. Baiker, J. Non-Crystal. Solids 134, 47 (1992)

34. K.J.A. Raj, Y.R. Smith, V. Subramanian, B. Viswanathan, Indian J. Chem. 49A, 867 (2010)

35. X. Fu, L.A. Clark, Q. Yang, M.A. Anderson, Environ. Sci. Technol. 30, 647 (1996)

36. X.W. Zhang, L.C. Lei, Chin. Sci. Bull. 53, 3339 (2007)

37. D.V. Kozlov, E.A. Paukshtis, E.N. Savinov, Appl. Catal. B 24, L7 (2000)

38. S.R. Kumar, C. Suresh, K.A. Vasudevan, N.R. Suja, P. Mukundan, K.G.K. Warrier, Mater. Lett. 38, 161 (1999)

39. I.W. Tanakulrungsamgk, M. Inoue, J. Mater. Sci. Lett. 19, 1439 (2000)

40. C. Anderson, A.J. Bard, J. Phys. Chem. B 101, 2611 (1997)

41. R. Grieken, J. Aguado, J. Photochem. Photobiol. A 148, 315 (2002)

42. M. Nakamura, Thin Solid Films 496, 131 (2006)

43. C. Xie, Z.L. Xu, Q.J. Yang, B. Xue, Y. Du, J. Zhang, Mater. Sci. Eng. B Solid 112, 34 (2004)

44. Y. Arai, K. Tanaka, A.L. Khlaifat, J. Mol. Catal. A Chem. 243, 85 (2006)

45. M. Maeda, S. Yamasaki, Thin Solid Films 483, 102 (2005)

46. M. Nakamura, M. Kobayashi, N. Kuzuya, T. Komatsu, T. Mochizuka, Thin Solid Films 502, 121 (2006)

47. C. Minero, F. Catozzo, E. Pelizzetti, Langmuir 8, 481 (1992)

48. X.T. Gao, S.R. Bare, J.L.G. Fierro, M.A. Banares, I.E. Wachs, J. Phys. Chem. B 102, 5653 (1998)

49. Y.M. Xu, W. Zheng, W.P. Liu, J. Photochem. Photobiol. A 122, 57 (1999)

50. X.T. Gao, I.E. Wachs, Catal. Today 51, 233 (1999)

51. C. Anderson, A.J. Bard, J. Phys. Chem. 99, 9882 (1995)

52. Z. Liu, J. Tabora, R.G. Davis, J. Catal. 149, 117 (1994)

53. M. Ahmad, J.R. Jones, L.L. Hench, Biomed. Mater. 2, 6 (2007)

54. S.S. Choi, B. Chu, S.G. Lee, S.W. Lee, S.S. Im, S.H. Kim, J.K. Park, J. Sol-Gel. Sci. Technol. 30, 215 (2004)

55. R.J. Davis, Z. Liu, Chem. Mater. 9, 2311 (1997)

56. R.W. Kessler, G. Krabichler, S. Uhl, D. Oelkrug, W.P. Hagan, J. Hyslop, F. Wilkinson, Opt. Acta 30(8), 1099 (1983)

57. H.K.A. Kan, T.P. Lin, J. Opt. Soc. Am. 60, 1252 (1970)

58. D. Oelkrug, W. Honnen, F. Wilkinson, C.J. Willsher, J. Chem. Soc. Faraday Trans. 2(83), 2081 (1987)

59. K.A. Balkis, T. Rajasekharan, M.V. Rajasekharan, J. Non-Cryst. Solids 352, 737 (2006)

60. M. Anpo, H. Nakaya, S. Kodama, Y. Kubokawa, K. Domen, T. Onishi, J. Phys. Chem. 90, 1633 (1986)

61. H. Yamashita, S. Kawasaki, Y. Ichihashi, M. Harada, M. Takeuchi, M. Anpo, G. Stewart, M.A. Fox, C. Louis, M. Che, J. Phys. Chem. B 102, 5870 (1998)

62. P.V. Kamat, Chem. Rev. 93, 267 (1993) 
63. J. Zhang, H. Yamashita, M. Anpo, Chem. Lett. 10, 1027 (1997)

64. T. Seko, K. Ogura, Y. Kawakami, H. Sugino, H. Toyotama, J. Tanaka, Chem. Phys. Lett. 291, 438 (1998)

65. S.R. Pujari, P.N. Bhosale, P.M.R. Rao, S.R. Patil, Matt. Res. Bull. 37, 439 (2002)

66. A.A. Gorman, I. Hamblett, R.J. Harrison, J. Am. Chem. Soc. 106, 6952 (1984)

67. T. Shida in Physical Sciences Data Vol. 34 (Elsevier Science, Amsterdam, 1988)

68. A. Vancea, Ph.D. Thesis, Loughborough University (2013)

69. H.J. Tobler, A. Bauder, H.H. Günthard, J. Mol. Spectrosc. 18, 239 (1965)

70. A.G. Anderson, B.M. Steckler, J. Am. Chem. Soc. 81, 4941 (1959)

71. T. Manna, S. Banerjee, S. Bhattacharya, Indian J. Chem. 49A, 1461 (2010)

Publisher's Note Springer Nature remains neutral with regard to jurisdictional claims in published maps and institutional affiliations.

\section{Affiliations}

\section{Anisoara Vancea ${ }^{1} \cdot$ lain Kirkpatrick ${ }^{2} \mathbb{D} \cdot$ David R. Worrall $^{1} \mathbb{D} \cdot$ Siân L. Williams ${ }^{1}$}

David R. Worrall

d.r.worrall@lboro.ac.uk

Iain Kirkpatrick

i.kirkpatrck@lboro.ac.uk

Siân L. Williams

s.l.williams@lboro.ac.uk

1 Department of Chemistry, Loughborough University, Epinal Way, Loughborough, Leicestershire LE11 3TU, UK

2 Department of Aeronautical and Automotive Engineering, Loughborough University, Epinal Way, Loughborough, Leicestershire LE11 3TU, UK 